\title{
MENINGKATKAN KEJUJURAN AKADEMIK: EFEKTIVITAS CLASSROOM DEVELOPMENTAL BIBLIOTHERAPY DALAM PEMBELAJARAN
}

\author{
S. Khorriyatul Khotimah*1, Mohamad Ivan Fadhli ${ }^{2}$, Yasin Habibi ${ }^{3}$ \\ ${ }^{1-3}$ Universitas Islam Negeri Sunan Ampel Surabaya, \\ ${ }^{1-3} \mathrm{Jl}$. A. Yani No. 117 \\ *khotim_psi@yahoo.com ${ }^{1}$, fadeliivan4@gmail.com ${ }^{2}$, habibisin@outlook.co.id ${ }^{3}$
}

\begin{abstract}
Academic honesty is one of character education that must be teached to our students integratedly in learning process. Bibliotherapy, especially developmental bibliotherapy is one of technics to teach values integrated in curriculum. This research aims is to find out the efectiveness of classrooom developmental bibliotherapy in Bahasa Indonesia learning to improve student's academic honesty. The type of this research is Quasi Experimental Reseacrh using Non Equivalent Control group Posttest Only Design. This research take 63 subjects on $4^{\text {th }}$ MI (Islamic Ememntary School) students. This research take two groups, devided into experimental and control groups. The treatment, CDB in learning was given to experimental group in four sessions. CDB is given integratedly in Bahasa Indonesia Learning with four steps: pre-reading, guided-reading, post-reading disscussion, and reinforcement/ problem solving. The measurement of academic honesty is using The Academic Honesty Schale, wich measure academic honesty in three aspecs; attitude, tendency and behavior. The test result through t-test shows that the data is significantly difference. It indicate that there is difference of cheating behavior on experiment group and control group. It means that there is influence of role playing method in learning to cheathing behavior on students.
\end{abstract}

Keywords: academic honesty, bahasa indonesia learning, classroom developmental bibliotherapy

\begin{abstract}
Abstrak
Kejujuran akademik merupakan salah satu nilai dalam pendidikan karakter yang harus diajarkan kepada siswa yang terintegrasi dalam proses pembelajaran. Biblioterapi, terutama biblioterapi perkembangan merupakan salah satu teknik untuk mengajarkan nilai yang terintegrasi dalam kurikulum. Tujuan penelitian ini adalah untuk menguji Efektifitas Classroom Developmental Bibliotherapy $(C D B)$ dalam Pembelajaran Bahasa Indonesia untuk meningkatkan kejujuran akademik pada siswa. Jenis penelitian ini adalah eksperiment kuasi dengan desain Non Equivalent Control Group Posttest Only Design. Subyek dalam penelitian ini sejumlah 63 siswa kelas IV MI (Madrasah Ibtidaiyah), yang dibagi dalam dua kelompok, kelompok eksperimen dan kontrol. Perlakuan CDB dalam pembelajaran diberikan pada kelompok eksperimen dalam empat sesi. CDB diberikan secara integratif dalam pembelajaran Bahasa Indonesia dengan empat tahapan, yaitu prabaca, membaca terbimbing, diskusi pasca baca dan penguatan/
\end{abstract}


pemecahan masalah. Pengukuran kejujuran akademik menggunakan Skala Kejujuran Akademik, yang mengukur kejujuran akademik dalam tiga aspek; sikap, kecenderungan dan perilaku untuk menghindari mencontek. Dari hasil uji-t diketahui bahwa terdapat perbedaan tingkat kejujuran akademik pada kelompok eksperimen dan kelompok kontrol. Hal ini berarti CDB dalam pembelajaran Bahasa Indonesia efektif untuk meningkatkan kejujuran akademik siswa.

Kata kunci: classroom development bibliotherapy, kejujuran akademik, pembelajaran bahasa indonesia

\section{Pendahuluan}

Kejujuran merupakan hal yang penting untuk diajarkan sejak dini pada anak didik, yang salah satunya adalah kejujuran akademik. Konsep kejujuran tidak mudah untuk dijelaskan, seseorang dikatakan jujur, jika tidak melakukan tindakan tidak jujur. Menurut Braun \& Stallworth (2009), kejujuran akademik adalah konsep yang dapat dipahami dari berbagai segi, yang memungkinkan banyak perilaku ketidakjujuran akademik diinterpretasi dan diperdebatkan. Kejujuran akademik dapat dipahami sebagai perilaku menghindari ketidakjujuran dalam menyelesaikan tugas akademik.

Mencontek merupakan salah satu bentuk ketidakjujuran akademik. Penelitian tentang perilaku mencontek anatara lain oleh Anderman \& Midgley (2004); Anderman, Cupp, dan Lane (2010); Semerci (2006); Davy, dkk (2007); Firmin, dkk (2006); Houser (1982); Houston (1977); Mazar, Amir, On, dan Ariely (2008); McCabe (1999); Murdock dan Hale (2001); Eisenberg (2004); Payan, 2010; Rourke, Barnes, Deaton, Fulks, Ryan, dan Rettinger (2010); Semerci (2006); Smith, dkk (1998); Tas dan Tekkaya (2010);Vinsk \& Tryon (2009). Bentuk lainnya adalah plagiasi, yang diantaranya diteliti oleh; Grijalva, dkk (2006); Ledwith \& Rizquez (2008), dan Ananou (2014).

Perilaku mencontek dan ketidak jujuran akademik lainnya menjadi fenomena yang sangat meresahkan, karena akan sangat merugikan pelakunya. Davis, dkk (2007) mengungkapkan bahwa secara akademik mencontek merugikan siswa karena guru tidak dapat mengukur dengan tepat kemampuan akademik siswa bahkan kompetensi lulusannya. Perilaku mencotek ini berakibat nilai ujian dan atau ijazah tidak dapat menggambarkan kompetensi siswa, sehingga ketika siswa melanjutkan pendidikan atau melamar pekerjaan, mereka akan ditempatkan di posisi sesuai nilai hasil mencontek, bukan kompetensinya. Berdasarkan permasalahan tersebut, diperlukan upaya untuk mengatasi perilaku mencontek.

Beberapa penelitian yang menunjukkan upaya untuk mengatasi ketidakjujuran akademik, diantaranya; penggunaan software anti-plagiat (Ledwith \& Risquez, 2008), penerapan cognitive dissonance intervention (Vinsk \& Tryon, 2009); penerapan Classroom control technique (Housser, 1982); mengungkap efek direct knowledge and attitude terhadap ketidak jujuran akademik (Rourke, dkk 2010). Secara umum penelitian-penelitian yang berupaya mengatasi ketidakjujuran akademik dapat dibedakan menjadi dua, yang melibatkan faktor eksternal (software anti-plagiat dan Classroom control technique) dan faktor internal (cognitive dissonance intervention dan direct knowledge and attitude). Di Indonesia upaya-upaya untuk mengatasi 
ketidakjujuran akademik lebih pada kontrol eksternal seperti, pengawasan ujian, tata tertib ujian dan hukuman.

Hal ini memberikan gambaran, untuk menghindari ketidakjujuran akademik perlu dikembangkan kejujuran akademik siswa. Peneliti tertarik untuk mengembangkan upaya meningkatkan kejujuran akademik siswa pada usia sekolah dasar. Hal ini didasarkan oleh pertimbangan bahwa beberapa penelitian menunjukkan perilaku mencontek dan ketidak jujuran akademik lainnya dilakukan mulai dari jenjang SD (Housser, 1982: Semerci: 2006). Semerci (2006) mengungkapkan bahwa masalah moral seperti mencontek dapat dimulai pada usia 10 and 11. Pada usia ini perlu untuk mengajarkan tentang kejujuran akademik secara sengaja pada siswa dengan mengembangkan cara berpikir dalam menghadapi pilihan dilematis untuk menyelesaikan tugas-tugas akademis secara jujur.

Kejujuran akademik dalam penelitian ini dipahami sebagai upaya menghindari mencontek. Penelitian Anderman \& Midgley (2004) tentang mencontek, menggunakan tiga indikator perilaku mencontek, yaitu: (1) perilaku mencontoh jawaban teman saat ualangan matematika; (2) mencontek dalam mengerjakan tugas matematika, dan (3) mencontoh jawaban teman dalam menyelesaikan tugas matematika. Anderman, dkk (2010) kemudian mengembangkannya menjadi lima indikator perilaku mencontek dalam kelas kesehatan, yang meliputi perilaku: (1) mencontoh buku dalam mengerjakan tugas; (2) mencontoh buku untuk mengerjakan kuis/ ulangan; (3) mencontoh catatan kecil saat ulangan; (4) mencontoh jawaban teman saat mengerjakan tugas; dan (5) mencontoh jawaban teman saat menyelesaikan ulangan. Berdasarkan paparan di atas, kejujuran akademik siswa dalam penelitian ini didefinisikan sebagai sikap, kecenderung dan perilaku menghindari mencontek dalam menyelesaikan tugas akademik dengan lima indikator yang dikemukakan oleh Anderman, dkk (2010) .

Penelitian ini menunjang pelaksanaan kurikulum 2013. Berdasarkan Salinan Lampiran Peraturan Menteri Pendidikan Dan Kebudayaan Republik Indonesia Nomor 54 Tahun 2013, Tentang Standar Kompetensi Lulusan Pendidikan Dasar dan Menengah disebutkan bahwa kompetensi lulusan SD/MI diharapkan memiliki kualifikasi kemampuan dalam aspek sikap yaitu memiliki perilaku yang mencerminkan sikap orang beriman, berakhlak mulia, berilmu, percaya diri, dan bertanggung jawab dalam berinteraksi secara efektif dengan lingkungan sosial dan alam di lingkungan rumah, sekolah, dan tempat bermain.

Pendidikan karakter adalah hal sangat penting untuk diajarkan pada generasi muslim, sebagaimana hadits nabi:

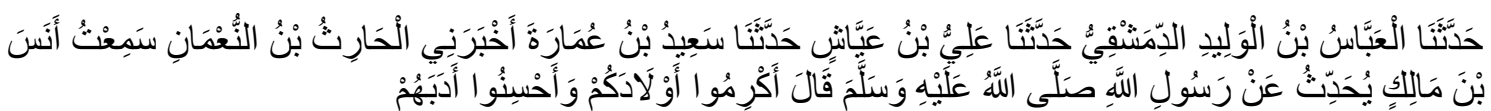
Artinya: "Muliakanlah anak-anakmu dan ajarkanlah mereka budi pekerti baik" (HR. Ibnu Majah).

Hadits tersebut menunjukkan bahwa orang tua ditugaskan untuk mengajarkan anak-anak dengan ahlak yang mulia. Guru dan sekolah sebagai partner dalam mendidik anak-anak juga berkewajiban untuk mengajarkan siswa ahlak yang mulia.

Di Indonesia, pendidikan karakter menjadi bagian penting dalam tujuan pendidikan, sebagaimana disebutkan dalam UU No. 20 Tahun 2003 tentang Pendidikan Nasional bahwa pendidikan adalah usaha sadar dan terencana untuk mewujudkan suasana belajar dan proses pembelajaran agar peserta didik secara aktif 
mengembangkan potensi dirinya untuk memiliki kekuatan spiritual keagamaan, pengendalian diri, kepribadian, kecerdasan, akhlak mulia, serta keterampilan yang diperlukan dirinya, masyarakat, bangsa dan negara. Kemediknas telah menerbitkan Pedoman Sekolah Pengembangan Pendidikan Budaya dan Karakter Bangsa (Kemendiknas, 2010) yang menempatkan tanggunng jawab sebagai salah satu dari 18 nilai yang harus dikembangkan oleh sekolah. untuk menunjang pelaksanaan pendidikan karakter.

Kejujuran adalah bagian dari karakter positif yang perlu dikembangkan pada diri siswa sejak usia dini, agar perilaku mencontek dan efek negatifnya dapat dihindari. Siswa akan menerapkan kejujuran dalam kegiatan sekolah dan kehidupan sehari-hari, dengan harapan akan berkembang menjadi individu dewasa yang jujur.

Mempertimbangkan pentingnya upaya untuk mencegah dan atau mengatasi ketidak jujuran akademik, maka salah satu hal yang perlu dipertimbangkan adalah meningkatkan penalaran moral siswa. Kohlberg (1976) mengungkapkan tentang peran kognitif terhadap perilaku. Menurut Kohlberg (1976), individu akan melalui enam tahapan moral, mulai dari tahap pertama yang mempertimbangkan perilaku sebagimana pandangan orang lain, sekaligus sebagai kontrol eksternal, hingga tahapan keenam yang teregulasi secara internal, pertimbangan moral individu didasarkan kontrol internal/ nilai-nilai internal yang diyakini. Demikian pula dengan ketidak jujuran akademik, kontrol eksternal akan efektif jika individu masih di level rendah, dan sebaliknya, semakin tinggi level penalaran moral individu, maka akan semakin tinggi regulasi internalnya.

Mempertimbangkan konsep moral dari Kohlberg (1976) yang mendasari perilaku siswa untuk melakukan kejujuran akademik atau ketidakjujuran akademik, maka peniliti mencoba menentukan suatu alternatif treatment yang dapat dilakukan dalam setting pendidikan, melalui pengembangan pengetahuan siswa (aspek kognitif) dalam mempertimbangkan aspek-aspek moral untuk meningkatkan kejujuran akademik pada siswa. Maka, alternatif treatment yang perlu dikembangkan adalah yang mendasar pada pendekatan kognitif-perilaku. Salah satu kegiatan yang mendasarkan pada pendekatan kognitif-perilaku adalah biblioterapi (Shechman, 2009).

Jenis biblioterapi yang digunakan adalah biblioterapi perkembangan, karena menurut McMillen (2006) biblioterapi perkembangan dapat digunakan dalam kelas yang bertujuan menfasilitasi perkembangan normal siswa atau untuk mengajarkan sikap, perasaan dan perilaku. Biblioteapi sering digunakan di sekolah adalah biblioterapi perkembangan (Afolayan, 1992). Dalam penelitian ini disebut Classroom Developmental Bibliotherapy $(C D B)$ yang diintegrasikan dalam pembelajaran Bahasa Indonesia karena menurut Johnson, dkk (2000) biblioterapi meningkatkan perkembangan berbahasa.

Treatment ini tepat diberikan pada siswa kelas IV sebagai upaya preventif. Piaget (2003) mengemukakan bahwa anak usia sekitar 10 tahun dalam penelitian ini kelas empat berada pada tahap operasional konkret $(7-11$ tahun) dimana anak mulai mengembangkan kemampuan untuk melihat situasi dalam berbagai sudut pandang. Treatment ini juga mengupayakan dukungan peran sosial yang diperlukan oleh anak pada usia ini, sebagaimana diungkapkan oleh Vygotsky (1986).

Berdasarkan berbagai kajian tentang kejujuran akademik dan pengembangannya melalui penggunaan $C D B$ dalam pembelajaran Bahasa Indonesia yang sekaligus untuk meningkatkan prestasi belajar Bahasa Indonesia yang telah dijelaskan sebelumnya, model hubungannya digambarkan berikut ini. 


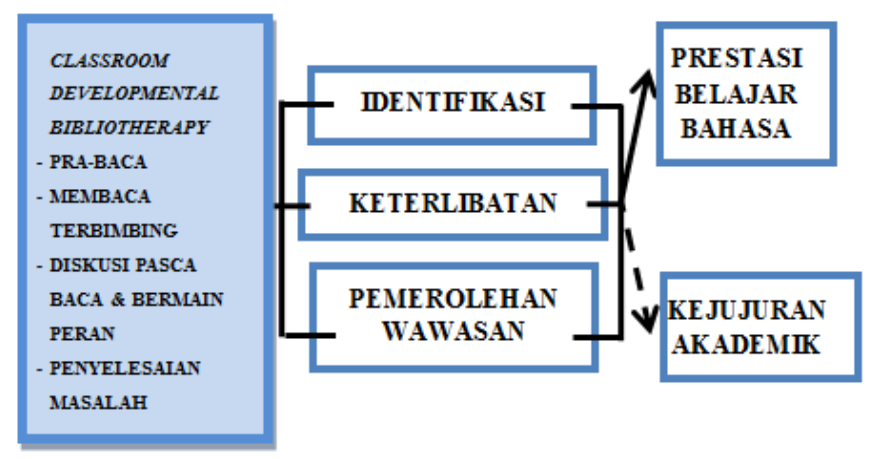

Gambar 1. Model hubungan $C D B$ dengan kejujuran akademik dan prestasi belajar Bahasa Indonesia

Keterangan:

$\rightarrow$ Instructional Effect

$\rightarrow$ Nurturance Effect

Tahapan $C D B$ yang diintegrasikan dalam pembelajaran Bahasa Indonesia adalah merupakan serangkaian tahapan biblioterapi yang dikembangkan berdasarkan penelitian Khotimah (2014) yang diadaptasi dari Forgan (2002) dan Iaquinta \& Hipsky (2006): (a) Prabaca: memotivasi dengan materi bacaan yang menarik dan beragam, (b) Membaca terbimbing: guru mengarahkan siswa dalam membaca, (c) Diskusi pascabaca dan bermain peran: siswa merefleksikan pengalaman pribadinya, kejadian dan emosi, dengan menceritakan kembali, menggambar, membuat jurnal, mencatat di organizer, berdiskusi dan bermain drama, serta (d) penyelesaian masalah/ penguatan: guru memberikan pertanyan-pertanyaan mendalam/ menyelidik tentang bacaan, insight yang diperoleh, dan isu-isu yang terkait dengan diskusi kelas, diskusi kelompok dan role playing. Keempat tahapan tersebut diintegrasikan dengan langkah pembelajaran yang dituangkan dalam RPP agar siswa dapat mengalami proses $C D B$.

Kegiatan membaca sebagai bagian inti dari $C D B$ - sejatinya terdapat dalam semua mata pelajaran, namun mata pelajaran yang secara khusus bertujuan untuk meningkatkan kemampuan membaca siswa dan mengevaluasinya, adalah pelajaran Bahasa Indonesia. Kegiatan memerankan drama pendek sebagai bagian dari kompetensi berbicara, juga memungkinkan untuk menyediakan stimulasi yang bervariasi dan tepat. Hal ini sesuai dengan yang disampaikan oleh Nucci (2006) bahwa untuk integrasi pendidikan karakter dalam kurikulum, pelajaran yang mendukung pertumbuhan moral melalui tugas-tugas tertentu dan diskusi reflektif atas isu terkait, yang salah satu alternatifnya adalah menggunakan kegiatan bermain peran, stimulasi dan tugas tertulis yang selanjutnya menggarahkan siswa pada kegiatan belajar aktif.

Berdasarkan hal tersebut, peneliti tertarik untuk melakukan penelitian eksperimen dalam bentuk upaya meningkatkan kejujuran akademik melalui pengembangan penalaran moral siswa dengan melibatkan kontrol eksternal dan internalisasi nilai-nilai melalui bibliotherapy dalam pembelajaran Bahasa Indonesia untuk siswa kelas IV SD. Jika sebelumnya guru menghadapi kesulitan dalam mengajarkan pendidikan karakter, berkaitan dengan hal lain dalam jadwal mengajar yang mensyaratkan ketepatan pada kemampuan akademik (Parker, 2005), maka dari hasil penelitian ini guru dapat mengetahui dan menggunakan model pembelajaran Bahasa Indonesia untuk mengajarkan kejujuran akademik bersamaan kompetensi akademik. 
Dalam penelitian ini, kegiatan memasangkan biblioterapi dalam kurikulum, disebut Classroom Developmental Bibliotherapy (CDB) sebagaimana Khotimah (2014), yang hasil penelitian tindakan kelasnya menyebutkan bahwa penggunaan $C D B$ dalam pembelajaran Bahasa Indonesia dapat meningkatkan kejujuran akademik siswa, khususnya pada kegiatan memerankan drama pendek. Dalam penelitian eksperimen ini, akan diuji efektifitas $C D B$ dalam pembelajaran Bahasa Indonesia untuk meningkatkan kejujuran akademik siswa. Rumusan masalah penelitian ini adalah "apakah classroom developmental biblioherapy dalam pembelajaran Bahasa Indonesia efektif untuk meningkatkan kejujuran akademik siswa kelas IV MI? “.

\section{Metode Penelitian}

Penelitian ini adalah eksperimen lapangan, yang bertujuan mengungkap pengaruh atau hubungan sebab akibat antar variabel dengan menguji hipotesis sebelumnya. Desain penelitiannya adalah Quasi Experimental Research, yaitu suatu penelitian eksperimen yang mendekati bentuk True Experiment dimana tidak terdapat kontrol atau manipulasi yang relevan pada semua variabel, melainkan hanya pada sebagian variabel (Salkind, 2006). Manipulasi dilakukan pada variabel bebas, yaitu pemberian perlakuan CDB dalam pembelajaran.

Variabel terikat dalam penelitian ini adalah kejujuran akademik yang diukur dengan Skala Kejujuran Akademik yang meliputi aspek sikap, kecenderungan dan perilaku. Skala Kejujuran Akademik tersebut mengadopsi dari penelitian sebelumnya (Khotimah, 2014).

Variabel bebas dari penelitian ini adalah $C D B$ yang diintegrasikan dalam pembelajaran Bahasa Indonesia dalam tema "cita-citaku" dengan kegiatan bermain drama, melalui 4 tahapan, yaitu: (1) prabaca, (2) membaca terbimbing, (3) diskusi pasca-baca dan bermain peran:, dan (4) penyelesaian masalah/ aktivitas penguatan. Untuk menunjang proses CDB yang dialami siswa, diberikan stimulasi melalui pertanyaan pelengkap dalam buku siswa meliputi: (1) identifikasi, (2) keterlibatan, dan (3) pemerolehan wawasan.

Desain penelitian yang digunakan adalah Nonequivalent Posttest Only Design, sebagai berikut:

\begin{tabular}{lccc}
\hline \multicolumn{1}{c}{ Kelompok } & Pretest & Treatment & Postest \\
\hline Eksperimen & - & $\mathrm{X}$ & $\mathrm{T} 2$ \\
Kontrol & - & - & $\mathrm{T} 2$ \\
\hline \multicolumn{2}{c}{ Keterangan: } \\
T2 & $=$ tingkat kejujuran akademik setelah perlakuan \\
$\mathrm{X}$ & $=$ perlakuan, pada kelompok eksperimen, diberikan dalam 4 pertemuan \\
- & $=$ tanpa perlakuan, pada kelompok kontrol
\end{tabular}

Treatment yang diberikan berupa penerapan CDB dalam Pembelajaran Bahasa Indonesia pada kegiatan bermain drama untuk tema 7 "Cita-citaku" bagi kelompok eksperimen dalam 4 kali pertemuan. Secara umum, tema cerita pada masing-masing kegiatan adalah: (1) Jujur Bermasyarakat, (2) Ayo Jujur Ayo Sehat, (3) Sahabatku, dan (4) Sahabatku. Kelompok kontrol mengikuti pembelajaran sebagamana biasanya (tanpa perlakuan). Selama treatment diberikan, juga dilakukan serangkaian observasi harian untuk memastikan keterlaksanaan CDB dalam pembelajaran dan peran aktif siswa 
selama treatment diberikan. Posttest pada kelompok eksperimen dan kelompok kontrol diberikan setelah 4 perlakuan.

Penelitian dilakukan di MI Cahaya Sidoarjo, pada pelajaran Bahasa Indonesia di Kelas IV. Subyek penelitian adalah siswa kelas IV-A dan kelas IV-B sejumlah 63 siswa. Pelaksanaan perlakuan pada pembelajaran Bahasa Indonesia pada Minggu ke empat Bulan Juli sampai dengan Minggu ke 3 Bulan Agustus 2016.

Skala Kejujuran akademik disajikan dalam bentuk self report, dimana siswa diminta untuk menjawab dengan memilih jawaban yang sesuai dengan dirinya yang diwakili dengan smiley dalam 5 skala jawaban; sangat setuju, setuju, ragu-ragu, tidak setuju, dan sangat tidak setuju, atau: sangat sesuai, sesuai, ragu-ragu, tidak sesuai, dan sangat tidak sesuai, sebagaimana instruksi pada masing-masing indikator.

Dalam kegiatan try out untuk menguji validitas dan reliabilitas alat ukur, peneliti melakukan uji coba alat ukur pada 91 siswa kelas IV (A, B, dan C). Aitem yang valid dari skala ini yang akan dipergunakan sebagai pengukuran kejujuran akademik siswa. Hasil uji korelasi product moment menujukkan bahwa 29 aitem valid sehingga dapat digunakan dalam penelitian ini dan satu aitem gugur (aitem 24). Instrumen untuk pengumpulan data adalah 29 aitem yang valid. Hasil uji reliabilitas skala kejujuran akademik menunjukkan nilai koefisien alfa sebesar 0,843 . Hal ini menunjukkan bahwa item-item pada skala perilaku mencontek tersebut reliabel dan dapat digunakan.

\section{Hasil dan Pembahasan}

Uji normalitas digunakan untuk mengetahui apakah data mempunyai distribusi normal atau tidak, dilakukan dengan Kolmogorov-Smirnov Test. Hasil uji normalitas pada kelompok eksperimen dengan nilai signifikansi 0,999 $(\operatorname{sig}>0,05)$ dan pada kelompok kontrol dengan nilai signifikansi 0,526 (sig> 0,05) menunjukkan bahwa data berdistribusi normal. Maka analisis data untuk mengungkap efektifitas CDB dalam pembelajaran untuk meningkatkan kejujuran akademik siswa dapat dilakukan dengan uji-t, hasilnya sebagai berikut ini.

Tabel 1.

Hasil uji t

\begin{tabular}{|c|c|c|c|c|c|c|c|c|}
\hline & \multicolumn{5}{|c|}{ Paired Differences } & \multirow{3}{*}{$-\mathbf{T}$} & \multirow[t]{3}{*}{ Df } & \multirow[t]{3}{*}{ Sig. (2-tailed) } \\
\hline & \multirow[t]{2}{*}{ Mean } & \multirow[t]{2}{*}{ Std. Dev } & \multirow{2}{*}{$\begin{array}{l}\text { Std. Error } \\
\text { Mean }\end{array}$} & \multicolumn{2}{|c|}{$\begin{array}{c}95 \% \text { Confidence Interval } \\
\text { of the Difference }\end{array}$} & & & \\
\hline & & & & Lower & Upper & & & \\
\hline Pair $1 \mathrm{~A}-\mathrm{B}$ & 6.333 & 12.134 & 2.335 & 1.533 & 11.133 & 2.712 & 26 & .012 \\
\hline
\end{tabular}

Dari hasil uji hipotesis pada tabel tersebut, diketahui nilai t hitung antara kelompok eksperimen dan kelompok kontrol 2,712 dengan nilai signifikansi 0,012 $(<0,05)$, menunjukkan bahwa terdapat perbedaan yang signifikan antara posttest kelompok eksperimen dengan posttest kelompok kontrol. Artinya CDB dalam pembelajaran efektif untuk meningkatkan kejujuran akademik siswa. Maka hipotesis " $C D B$ dalam pembelajaran efektif untuk meningkatkan kejujuran akademik siswa" diterima.

Sebagai pengembangan dari Penelitian Tindakan Kelas sebelumnya (Khotimah, 2014), hasil penelitian eksperiman ini telah menunjukkan kemajuan bahwa $C D B$ dalam 
pembelajaran Bahasa Indonesia efektif untuk meningkatkan kejujuran akademik siswa. Peningkatan kejujuran akademik siswa dimungkinkan karena beberapa hal.

Pertama, penggunaan $C D B$ yang dikembangkan dari Developmental Bibliotherapy tepat untuk mengajarkan nilai-nilai kejujuran pada siswa sebagai bagian dari pendidikan karakter secara integratif dalam pembelajaran. Hal ini sesuai dengan yang dikemukakan oleh Parker (2005) bahwa biblioterapi efektif dalam mengimplementasikan pendidikan karakter dalam kurikulum. Hal ini didukung oleh pendapat Bouley dan Godrey (2008) bahwa kegiatan biblioterapi dapat mengarahkan siswa untuk menginternalisasi nilai. Lucas \& Soares (2013), McMillen (2006), McCullins \& Chamberlain (2013) juga memaparkan penggunaan biblioterapi perkembangan di kelas yang bertujuan menfasilitasi perkembangan normal siswa atau untuk mengajarkan sikap, perasaan dan perilaku tertentu. Hal ini dikuatkan oleh Penerapan $C D B$ dalam pembelajaran Bahasa Indonesia pada tema 7 "Cita-citaku" dapat terlaksana dengan baik yang ditandai kegiatan pembelajaran yang aktif, berkembang dan ketercapaian indikator pembelajaran yang ditandai prestasi belajar siswa pada materi ini juga baik. Hasil penelitian ini diketahui bahwa CDB dalam pembelajaran efektif untuk meningkatkan kejujuran akademik siswa. Keterbatasan dari penelitian ini adalah, belum diketahui keajegan atau daya tahan pengaruh tersebut sehingga dapat dikembangkan pada penelitian berikutnya.

Kedua, penerapan $C D B$ sangat tepat dalam mengembangkan penalaran moral siswa akan nilai-nilai kejujuran melalui pendekatan kognitif-perilaku. Salah satu tindakan yang mendasarkan pada pendekatan kognitif-perilaku adalah biblioterapi (Shechman, 2009). Hal ini dikuatkan oleh McCullins \& Chamberlain (2013) bahwa salah satu kegunaan biblioterapi di sekolah adalah memfasilitasi perekembangan keterampilan kognitif siswa.

Pendekatan kognitif-perilaku menjadi alternatif yang tepat karena menurut Santrock (2004) pendekatan ini mengarahkan individu untuk memonitor, mengatur, dan mengelola perilaku mereka sendiri daripada membiarkannya dikontrol oleh faktor eksternal. Hal ini sejalan dengan konsep perkembangan moral berupa "internalisasi" bahwa perkembangan moral individu bergerak dari dorongan eksternal yang takut akan hukuman menjadi dorongan internal (Kohlberg, 1976).

Kegiatan biblioterapi sebagai pendekatan kognitif-perilaku, siswa mengambil pelajaran dari bahan bacaan yang disediakan tentang nilai-nilai kejujuran, sehingga dengan pengetahuan itu, siswa dapat mengimplementasikannya dalam pertimbangan moral ketika dihadapkan pada dorongan ekstrinsik untuk melakukan ketidakjujuran akademik, siswa akan cenderung mempertahankan konsep diri yang jujur, meningkatkan kompetensi akademiknya, dan mempertahankan kejujuran akademiknya. Hal ini nampak dalam diskusi kelas selama treatment dimana sebagian besar siswa telah dapat mengungkapkan pendapat untuk mempertahankan kejujuran disertai alternatif solusi untuk menyelesaikan masalah dilematis yang diketengahkan.

Ketiga, kesesuaian dengan karakteristik perkembangan anak secara kognitif dan sosial emosional juga mendukung peningkatan kejujuran akademik siswa. Menurut Piaget (2003) pada usia ini anak berada pada tahap operasional konkret, dimana selama tahap operasional konkret, anak belajar untuk mengembangkan kemampuan untuk melihat situasi-situasi dari berbagai sudut pandang. Cara berpikirnya menjadi lebih logis dan abstrak, perhatiannya meningkat dan ingatannya menjadi lebih efisien seiring mereka mengembangkan strategi-strategi baru. Hal ini dapat terlihat ketika peneliti menyediakan bacaan yang mengarahkan siswa untuk melihat pentingnya kejujuran 
akademik dari beberapa kisah yang berbeda dengan sudut pandang yang variatif, siswa dapat mempelajarinya.

Penggunaan biblioterapi diintegrasikan dengan pembelajaran mendukung penguasaan tugas yang menunjang sense of industry pada anak di usia ini sehingga akan cenderung termotivasi untuk berprestasi dan menghindari mencontek. Sutherland \& Arbuthnot (1991) menguatkan bahwa anak-anak pada tahap ini menentukan untuk menguasai tugas yang diberikan padanya. Pengembangan kejujuran akademik membuat anak-anak akan lebih fokus untuk meningkatkan kemampuannya atau menuntaskan tugasnya sehingga dapat mengembangkan orientasi penguasaan (mastery-orientation)

Keempat, terselenggarakannya kegiatan bermain peran dalam bentuk memerankan drama pendek pada setiap sesi treatmen. Kegiatan memerankan drama pendek memberikan siswa kesempatan untuk mengeksperesikan pikiran dan perasaannnya. Sebagaimana Lucas \& Soares (2013) menyampaikan bahwa dalam menyajikan biblioterapi siswa perlu diberikan kesempatan untuk mengekspresikan diri dalam merefleksikan hasil membacanya.

Penerapan $C D B$ dalam pembelajaran pada penelitian ini, disamping kegiatan membaca, kegiatan pembelajaran dan penilaiannya dilakukan secara verbal dengan mempraktekkan drama pendek, sehingga siswa dapat mengalami proses $C D B$ dan mengungkapkannya. Siswa mengenali tokoh dan kejadian dalam cerita lebih mendalam melalui kegiatan belajar dan mempraktekkan drama pendek dengan ekspresi dan penghayatan yang sesuai sehingga siswa lebih terfasilitasi dalam merasakan hubungan dengan cerita dan secara emosional terlibat dengan karakter tokoh utama hingga akhirnya siswa menyadari masalah yang dialaminya mirip dengan cerita tersebut (Khotimah: 2014). Hal ini sesuai dengan pendapat Krajewski (1999) bahwa drama dan dialog eksperiensial dapat meningkatkan pendidikan karakter karena menstimulasi pengalaman belajar siswa.

Kelima, disediakannya cerita rumpang berupa naskah drama yang belum selesai untuk diteruskan oleh siswa, memberikan siswa kesempatan untuk berlatih mengembangkan kemampuan menyelesaikan masalah dilematis yang dihadapi tokoh dalam cerita. Penyajian tugas ini dengan proses yang telah didesain sebelumnya dengan penugasan mandiri dan berkelompok. Hal ini sesuai pendapat dengan Lucas \& Soares (2013) bahwa dalam client-developmental bibliotherapy siswa perlu diberikan kesempatan untuk kreatif mengembangkan akhir cerita yang berbeda dan imajinatif dengan berdiskusi untuk membuat perubahan yang spesifik pada cerita. Hal ini tampak pada akhir cerita yang dikembangkan menunjukkan keterampilan pemecahan masalah yang mengarah pada kejujuran akademik dan mengembangan solusi yang kreatif dengan belajar di sisa waktu, menyampaikan terima kasih atas penyadaran untuk jujur, dan lain-lain.

Keenam, minat siswa. Dalam kegiatan belajar, siswa menunjukkan minat yang tinggi terhadap kegiatan $C D B$ yang diberikan. Tersedianya media pembelajaran yang cukup lengkap, diantara Buku Siswa yang bergambar dan disesuaikan dengan karakteristik siswa, dan penggunaan media power point presentation (ppt) untuk mendukung pembelajaran. Hal ini sangat membantu untuk mempertahankan perhatian siswa dan mendapatkan minat siswa terhadap naskah, kegiatan CDB dan materi pelajaran. Hal ini sesuai dengan saran dari McCullins \& Chamberlain (2013) agar menggunakan media bergambar untuk mendapatkan minat siswa. Guru memberikan siswa kesempatan untuk mengembangkan drama dengan menggunakan alat bantu bebas dalam penyajian $C D B$. Siswa menggunakan beberapa peralatan yang ada di kelas untuk 
menunjang tampilannya. Lucas \& Soares (2013) menyatakan agar guru memberikan siswa kesempatan untuk mengekspresikan pemikirannya sebagai refleksi atas bacaan yang dibacanya. Siswa dalam penelitian ini dapat mengekspresikan dirinya dengan memerankan drama sehingga menunjang proses $C D B$ dalam dirinya.

Ketujuh, dukungan dari pengelola madrasah juga menunjang hasil penelitian ini. Harapannya, dapat meningkatkan kejujuran akademik siswa dan mengembangkan pendidikan karakter yang terintegrasi dalam pembelajaran. Menurut Eisenberg (2004), para pendidik dan pihak sekolah senantiasa berusaha untuk mengurangi perilaku mencontek siswa. Tas \& Tekkaya (2010) mengungkapkan bahwa salah satu yang berpengaruh terhadap perilaku mencontek adalah classroom goal structure.

Dukungan pihak madrasah ini turut menguatkan norma sekolah dan kelas. Norma kelas mempengaruhi perilaku siswa untuk mencontek atau tidak (Eisenberg, 2004). Pada kelas yang memandang siswa yang tidak mau mencontek sebagai orang yang bodoh dan yang tidak memberi contekan sebagai orang yang egois, maka siswa akan cenderung mencontek. Maka hal ini juga akan berlaku sebaliknya.

Sebagaimana disampaikan oleh McMillen (2008) bahwa biblioterapi perkembangan dapat digunakan di kelas yang bertujuan memfasilitasi perkembangan normal siswa untuk mengajarkan sikap perasaan dan perilaku. Kegiatan belajar dengan $C D B$ telah menguatkan kejujuran akademik menjadi norma kelas dan orientasi kelas sebagai dukungan sosial. Menurut Nucci (2006), hal ini memungkinkan karena emosi terintegrasi ketika siswa mengkonstruk pengetahuan moralnya, dan proses tersebut dipengaruhi oleh iklim moral dan kepercayaan. Nucci (2006) menambahkan bahwa interaksi yang berkaitan dengan moralitas, cenderung berdampak pada kesejahteraan orang-orang disekitarnya. Interaksi dalam kegiatan belajar tersebut memungkinkan siswa membangun norma kelas dan orientasi kelas yang mendukung kejujuran akademik, oleh karena itu, penerapan $C D B$ dalam pembelajaran dapat menguatkan norma kelas untuk meningkatkan kejujuran akademik melalui pengembangan sikap, perasaan dan perilaku siswa.

\section{Simpulan}

Berdasrkan hasil penelitian disimpulkan bahwa $C D B$ dalam pembelajaran Bahasa Indonesia efektif untuk meningkatkan kejujuran akademik siswa. CBD sebagai bagian dari pendekatan kognitif -perilaku, merupakan pengembangan dari biblioterapi perkembangan, tepat untuk mengajarkan nilai-nilai kejujuran pada siswa secara integratif dalam pembelajaran. Kegiatan CDB tersebut menunjang proses internalisasi dalam penalaran moral siswa yang mengarahkan mereka untuk dapat memonitor, mengatur, dan mengelola perilaku mereka sendiri daripada membiarkannya dikontrol oleh faktor eksternal, sehingga siswa akan mencari solusi yang jujur ketika dihadapkan pada pilihan dilematis untuk mencontek. Perkembangan penalaran moral siswa dalam proses $\mathrm{CDB}$ ini menunjang pengembangan norma kelas dan norma sekolah sehingga semakin menguatkan kejujuran akademik siswa. Penelitian berikutnya disarankan agar melakukan penelitian eksperimen dengan desain time series untuk mengetahui apakah treatment tersebut dapat memberikan pengaruh dalam jangka waktu yang lebih lama, selain itu disarankan guru untuk menggunakan dan mengembangkan $C D B$ dalam Pembelajaran Bahasa Indonesia dan pelajaran lainnya. 


\section{Daftar Pustaka}

Afolayan, J. A. (1992). Documentary Perspective of Bibliotherapy in Education, Reading Horizons, 33 (1).

Ananou, T. S. (2014). Academic Honesty in The Digital Age, Dissertation, Indiana University of Pnsylvania, Published by ProQuest.

Anderman, E. M \& Midgley, C. (2004). Changes in Self- Reprted Academic Cheating Across The Transition from Middle School to High School, Contemporary of Educational and Counseling Psychology, 29: 499-517.

Anderman, E. M., Cupp, P. K \& Lane D. (2010). Impulsivity and Academic Cheating, The Journal of Experimental Education, 78: 135-150.

Braun, R.L. \& Stallworth, H. L. (2009). The Academic Honesty Expectations Gap: An analysis of accounting Student and Faculty Perspectives, The Accounting Educators' Journal, 19: 127-141.

Davis, S. F., Drinan, P. P., \& Gallant, T. B. (2007). Cheating in School, WilleyBlackwell, Uniteg Kingdom

Davy, J. A., Kincaid, J. F., Smith, K. J. \& Trawick, M. A. (2007). An Examination of the Role of Attitudinal Characteristics and Motivation on the Cheating Behavior of Bussiness Students, Ethics \& behavior, 17 (3)

Eisenberg, J. (2004). To Cheat or not to Cheat: Effects of Moral Perspective and Situational Variables on Students' Attitudes, Journal of Moral education, 33:2

Firmin, M. W., Burger, A., Blosser, M. (2006), Affective Responses of Students Who Witness Classroom Cheating, Educational Research Quarterly, 32.3.

Grijalva, Therese C., Nowel, Clifford, Kerkvliet, Joe. (2006). Academic Honesty and Online Courses, College Student Journal, 40 (1).

Heath, M. A., Sheen, D., Leavy, D., Young, E., Money, K. (2005). Bibliotherapy: A resource to facilitate Emotional Healing and Growth, school Psychology International, 26: 563-580.

Houser, B. B. (1982). Student Cheating and Attitude: A Function of Classroom Control technique, contemporary Educational Psychology 7, 113-123

Houston, J. P. (1977). Four Components of Rotter's Internal-External Scale and Cheating Behavior, Contemporary Educational Psychology 2: 275-283.

Forgan, J. W. 2002. Bibliotherapy to Teach Problem Solving, Intervention in School and Clinic, 38 (2) : 75-82.

Iaquinta, A. and Hipsky, S. (2006) Practical Biblioherapy Strategies on the Inclusive Elementary Classroom, Early Childhood Education Journal, 34.

Johnson, C. E., Wan, G., Templeton, R. A., Graham, L. P., And Sattler. J. L. 2000. "Book it" to Peace: Bibliothherapy Guidelines for Teachers, Paper, Collage of Education \& Health Sciences, Bradley University, Peoria, Illinois. 
Khotimah, S. K. (2014). Penerapan Classroom Developmental Bibliotherapy dalam Pembelajaran Bahasa Indonesia Untuk Meningkatkan Kejujuran Akademik Siswa Kelas V MI Cahaya, Disertasi, Universitas Negeri Malang.

Kohlberg, L. (1976). Moral Stages and Moralization, The Cognitif Development Approach, Moral Development and Behavior, Theory, Research and Social Issues, Lickona, T (Editor), New York: Holt, Rinehart and Winston.

Krajewski, B. (1999). Enhancing Character Education Through Experiential Drama and Dialogue, NASSP Bulletin, 83 (40).

Ledwith, A., \& Risquez, A. (2008). Using Anti-Plagiarism Software to Promote Academic Honesty in The Context of Peer Reviewed Assigment, Studies in Higher Education, Vol.33, No.4, p371-384

Lucas, C. V., \& Soares, L. (2013). Bibliotherapy: a Tool to Promote Children Psychological Well being, Journal of Poetry Therapy, Vol 26, No. 3, 137-147

Mazar, N., Amir, On \& Ariely D. (2008). The Dishonesty of Honest People : A Theory of Self -Concept Maintenance, Journal of Marketing research, 155: 633-644.

McCabe, D. L. (1999). Academic Honesty Among High School Students, Adolescence, 34 (136).

McCullins, D., \& Chamberlain, D. (2013). Bibliotherapy for Youth and Adolescent_School-Based Aplication Research, Journal of Poetry Therapy, Vol26, No.1, 13-40

McMillen, P. S. (2006). A Therapiutic Collaboration: The Bibliotherapy Education Project at Oregon State University, Faculty Publications (Libraries), University of Nevada, Las Vegas.

McMillen, P. S. (2008). The Bibliotherapy Education Project Alive and WellPerpectually "Under Construction", Behavioral Social Science Librarian, 27 (1), The Harworth Press.

Murdock, T. B, Hale. (2001). N. M. And Weber, M. J., Predictors of Cheating among Early Adolescents : Academic and Social Motivation, Contemporary Educatinal Psikology, 26: 96-115.

Neuman, (2000). Social Research Methods, Boston: Allyn and Bacon.

Nucci, L. (2006). Handbook of Moral Development, Education For Moral Development, Killen, M \& Simetana J (Editor), New Jersey: Lawrence Erbaum Associates Inc

Payan, J., Reardon, J. \& McCorkle, D, E. (2010). The Effect of Culture on Academic Honesty of Marketing and Bussiness Students, Journal of Marketing Education, 32: 275.

Parker, K. L. (2005). Reading for Caracter: Principles of Bibiliotherapy Applied to Children Literature, Faculty Publications and Presentations, Paper 2

Piaget. (2003). The Psychology of Intelligence, diterjemahkan oleh Piercy, M., \& Berlyne, D. E., British: Taylor and Francis e- Library. 
Rourke, J. O., Barnes, J, Deaton, a., Fulks, K., Ryan K. Rettinger, D, A. (2010) Imitation Is the Suncerest form of Cheating: The Influence of Direct Knowledge and attitudes on Academic Dishonesty, ethics \& Behavior, 20(1)

Salkind, N. J. (2006) Exploring Research, Pearson International Editon.

Santrock, J. W. (2004). Educational Psychology, (2nd ed), New York: Mc Graw-Hill.

Shechtman, Z. (2009). Treating Child and Adolescent Agression Through Bibliotherapy, New York: Springer

Semerci, C. (2006). The Opinion of Medicine Faculty Students Regarding Cheating in Relation to Kohlberg's Moral development Concept, Social Behavior and Personality, 34(1). 41-50

Smith, Jimmie, N., Nolan, Rebecca, F., Dai \& Yong, (1998). Faculty Perception of Student Academic Honesty, College Student Journal, 32 : 2

Tas, Y and Tekkaya, C. (2010). Personal and Contextual Factors Associated with Students' Cheating in Science, The Journal of Experimental Education, Vol 78, p440-463

Vygotsky, L. (1986). Thought and Language, (Edited by Kozulin, A), Cambridge: The MIT Press.

Vinsk, E. J., \& Tryon, G. (2009). Study of Cognitive Dissonance Intervention to Address High School Students' Cheating Attitudes and Behaviors, Ethics \& Behavior, 19(3): 218-226 